\title{
Anabases
}

ANABASES Traditions et réceptions de l'Antiquité

$23 \mid 2016$

Varia

\section{Deux regards sur la place de l'Antiquité au collège}

\section{(2) OpenEdition \\ 1 Journals}

Electronic version

URL: http://journals.openedition.org/anabases/5644

DOI: 10.4000/anabases.5644

ISSN: 2256-9421

Publisher

E.R.A.S.M.E.

\section{Printed version}

Date of publication: 2 May 2016

ISSN: 1774-4296

\section{Electronic reference}

"Deux regards sur la place de l'Antiquité au collège », Anabases [Online], 23 | 2016, Online since 04 May 2016, connection on 23 September 2020. URL : http://journals.openedition.org/anabases/5644 ; DOI : https://doi.org/10.4000/anabases.5644

This text was automatically generated on 23 September 2020

(c) Anabases 


\section{Deux regards sur la place de l'Antiquité au collège}

1 À l'heure où une nouvelle réforme du collège promeut l'interdisciplinarité et la transversalité des connaissances et des compétences, les deux articles qui suivent proposent un double regard sur la place de l'Antiquité au collège, dans les programmes d'histoire d'une part, dans les enseignements de langues et cultures de l'Antiquité d'autre part. Leurs auteures replacent la question dans une perspective historique, tout en s'appuyant sur leur expérience de l'enseignement, puisqu'elles sont toutes deux professeures en collège.

2 Ces articles ont été rédigés au moment où les programmes étaient en cours d'élaboration, plusieurs versions ayant été proposées. Ils montrent que l'Antiquité, autrefois enseignée en histoire et en lettres se diffuse désormais dans des dispositifs transversaux : en histoire des arts et dans les Enseignements pratiques interdisciplinaires (EPI), comme celui de langues et cultures de l'Antiquité, dans lequel l'Antiquité peut être abordée en éducation physique et sportive, en physique-chimie ou en mathématiques. Mais la place désormais dévolue à l'enseignement des langues anciennes soulève dès lors des interrogations. L'Antiquité conserve quant à elle sa place dans l'enseignement de l'histoire, en classe de sixième, avec une approche cependant renouvelée. 